\title{
ASSESSMENT OF DENTAL FLUOROSIS IN CHILDREN OF JAIPUR DISTRICT, RAJASTHAN, INDIA
}

\author{
CHETRAM MEENA ${ }^{1 \#, ~}$, SUMAN RATHORE ${ }^{1 \#, ~}$ SUPRIYA DWIVEDI $^{1}$, ZAOZIANLUNGLIU GONMEI $^{2}$, TOTEJA GS ${ }^{3 *}$, \\ KUMUD BALA ${ }^{1}$, MOHANTY SS ${ }^{3}$
}

\begin{abstract}
${ }^{1}$ Department of Biotechnology, Amity Institute of Biotechnology, Amity University, Noida - 201 303, Uttar Pradesh, India. ${ }^{2}$ Department of Foods and Nutrition, Amity Institute of Food Technology, Amity University, Noida - 201 303, Uttar Pradesh, India. ${ }^{3}$ Department of Biotechnology, Desert Medicine Research Centre, Indian Council of Medical Research, Jodhpur - 342 005, Rajasthan, India. Email: gstoteja@gmail.com
\end{abstract}

Received: 03 April 2017, Revised and Accepted: 28 April 2017

\section{ABSTRACT}

Objective: The objective of the present study was carried out to explore the potential association between fluoride concentration in drinking water and severity of dental fluorosis (DF) in the children.

Methods: The study of DF in the children (6-14 years old) was conducted in the two blocks (a) Jamwa Ramgarh block in; Heerawala, Palera, Nayabas, Saipur and Birasana, (b) Amber block in; Jugalpura, Chitanukalan, Sunder ka bas, Peelwa and Sirsali of Jaipur district, Rajasthan, India of the study villages. Totally, 150 children were surveyed. The role of fluoride (F) levels in drinking water in the etiology of DF and the cases of DF in both dentitions and teeth were also assessed using Dean's classification. The fluoride (F) concentration in source of drinking water was estimated by fluoride (F) ion specific electrode (Thermo Scientific Orion Star A329, USA).

Results: The F concentration in (Tube well and Hand pump) water ranges from 0.7 to 15.0 parts per million (ppm) in Jamwa Ramgarh block and 1.40-5. 10 ppm in Amber block. The prevalence of DF 27 (36\%) in Jamwa Ramgar block and 26 (34.66\%) in Amber block out of 75 children were examined in each block. Significantly increase in levels of F in drinking water is positively correlated with DF.

Conclusion: This study finding has shown the relation of DF to high fluoride (F) levels in drinking water sources. A higher fluoride (F) levels in source of drinking water is a major risk factor for DF. In view of the severity of the problem, the intake of calcium-rich foods and defluoridation techniques may help reducing risk of DF in the children.

Keywords: Dental fluorosis, Dean's classification, Jaipur district.

(c) 2017 The Authors. Published by Innovare Academic Sciences Pvt Ltd. This is an open access article under the CC BY license (http://creativecommons. org/licenses/by/4. 0/) DOI: http://dx.doi.org/10.22159/ajpcr.2017.v10i8.18875

\section{INTRODUCTION}

Fluorine is the most abundant electronegative element in nature, and about $(96 \%)$ of fluoride (F) in the human body is found in bones and teeth [1]. In India, fluorosis is the most prevalent endemic disease which coexists in certain geographical regions in the country. Fluorosis is mainly of three type, namely, dental, skeletal fluorosis (SF), and nonskeletal fluorosis (NSF). Dental fluorosis (DF) is a global disease is not new to India, the reason being the shortage of good quality portable water and consumption of fluoride (F) enriched water by people both in the rural and urban areas [2]. A higher level of $\mathrm{F}$ exerts a negative effect on the metabolic processes and an individual may suffer from SF, DF, and NSF problem or a combination of the all [3]. Fluoride (F) is toxic to all the systems and causes hyperlipemia, lipid peroxidation, and oxidative stress in various tissues of the human body [4]. In the human body, fluoride enters through the drinking water, food, beverages, tea, fish, dental products, etc [5]. Dentifrices contain 1000 parts per million (ppm) fluorides [6]. Risk of endemic fluorosis was the F level in source of drinking water is more than $1.0 \mathrm{ppm}$ [7]. The available study data suggest that 15 States in India are endemic for fluorosis (F level in drinking water $>1.5 \mathrm{ppm}$ ) and about (62 million) people in India suffering from dental, SF and NSF including these 6 million children are below the age of 14 years [8].

$\mathrm{DF}$ in varying degree has been reported in drinking water with various concentrations of $\mathrm{F}$ levels [9-15]. The epidemiological study was conducted by Dean in the year 1930s demonstrated the relationship between the prevalence of mottling and the level of $\mathrm{F}$ in source of drinking water. The standard classification of the degree of mottling such as normal, questionable, very mild, mild, moderate, and severe was proposed by Dean [16-20]. DF is mostly seen in children when the $\mathrm{F}$ exposure is between (1 to 4 years) of age and mostly occurs in children below the 12 years of age [21].

Rajasthan is highly affected from fluorosis. Almost all 33 districts are endemic for fluorides [22]. A higher level of fluoride (F) in source of drinking water was also found in rural areas of Northern Rajasthan [23]. Ingestion of excess F-contaminated drinking water caused different types of fluorosis. Very few studies have been published in the field of fluorosis. Hence, the objective of the present study was to assess the DF in the children of Jaipur district, Rajasthan, India.

\section{METHODS}

\section{Study areas}

The study was conducted in the two blocks (a) Jamwa Ramgarh block in; Heerawala, Nayabas, Palera, Saipur and Birasana (b) Amber block in; Jugalpura, Chitanukalan, Sunder ka bas, Peelwa and Sirsali of Jaipur district, Rajasthan, India. Drinking water fluoride (F) levels of more than 1.5 ppm, respectively (Ministry of Drinking Water and Sanitation (MDWS), Government of India and Public Health and Engineering Department (PHED), Government of Rajasthan, Jaipur).

Total 150 male and female children (6-14 years) old exhibiting DF consuming F-contaminated water in endemic fluorosis areas of Jaipur district, Rajasthan, India were selected through a villagelevel survey was conducted. A pretested questionnaire regarding their socio-demographic, knowledge attitude and practices on defluoridation and fluorosis mitigation, source of drinking water was prepared. 
All children were examined for DF using the Dean's method [24]. According to specific clinical diagnostic criteria of development of fluorotic enamel opacities for DF was categorized as normal (Grade 0), questionable (Grade 1), very mild (Grade 2), mild (Grade 3), moderate (Grade 4), and severe (Grade 5). Children who were diagnosed as a Grade 0 or 1 classified as controls, whereas those who were diagnosed as Grade 2, 3, 4, or 5 DF cases.

\section{Collection of water sample and analysis}

Source of drinking water (Tube well and Hand pump) was collected in plastic tubes (Tarsons, India) and investigate for fluoride levels. Fluoride (F) concentration in each of the prepared solutions was estimated with the help of an F ion specific electrode (Thermo Scientific Orion Star A329, USA). Deionized water was used for all measurements.100 ppm fluoride stock (Thermo Scientific, USA) was used for calibration to prepare four standard solutions of different $\mathrm{F}$ concentration such as $(10,1,0.1$, and $0.01 \mathrm{ppm})$ by serial dilution

$1 \mathrm{~mL}$ of total ionic strength adjustment buffer III solution (Thermo Scientific, USA) was added to each $10 \mathrm{~mL}$ of standard solution and the instrument was calibrated. Fluoride estimation in the drinking water was carried out potentiometrically with a fluoride $(F)$ ion specific electrode (Thermo Scientific Orion Star A329, USA) using the method of Hall et al. [25].

\section{Ethical clearance}

This study protocol was approved by the Institutional Ethical Committee of Desert Medicine Research Centre, Jodhpur, Rajasthan, India. All the research work was performed according to the guidelines of Indian Council of Medical Research, New Delhi, India for human experimentation in biomedical research. An informed and written consent were obtained from the each participant or their parents or legal guardians.

\section{RESULTS}

Fluorosis is a major problem in India as well as in Rajasthan. The study area is Jaipur district, Rajasthan, India. Age of the children ranged from (6-14 years) old were selected for the study.

\section{DISCUSSION}

Totally, 150 children were involved from the two blocks of the rural area of Jaipur district, Rajasthan, India. Each block was divided into 5 villages. Total 10 villages were involved in the study from each village 15 children were involved in this study protocol. The village wise household survey was also carried out to estimate the fluoride content in the source of drinking water in the both block of the Jaipur district, Rajasthan. The highest amount of the fluoride content was estimated in Birasana village which ranges from (2.5-15 ppm) followed by Saipur (2.20-9.50 ppm), Palera (1.00-2.80 ppm), Heerawala (0.8-2.70 ppm) and Nayabas (0.7-2.10 ppm) in Jamwa Ramgarh block of the Jaipur district, Rajasthan Table 1. Household survey was also carried out in Amber block of Jaipur district to estimate the fluoride content in the source of drinking water. The highest amount of the fluoride content was estimated in Sirsali village which ranges from $(2.20-5.10 \mathrm{ppm})$ followed by Peelwa (0.80-3.50 ppm), Sunder ka bas (0.90-2.50 ppm), Jugalpura (0.80-2.50 ppm) and Chitanu kalan (1.40-2.20 ppm) in Amber block of Jaipur district, Rajasthan Table 2.

DF cases are higher in Birasana village according to Deans classification grading (Fig. 1) normal (2), questionable (3), very mild (2), mild (3). Moderate (3) and severe (2) village followed by Saipur, normal (3), questionable (5), very mild (3), mild (3) and moderate (1) Palera normal (4), questionable (6), very mild (2) and mild (3), Heerawala normal (8), questionable (4), very mild (2) and mild (1), and Nayabas normal (10), questionable (3), very mild (2) and over all the prevalence of DF 27 (36\%) in Jamwa Ramgarh block out of 75 children were examined (Table 3). DF cases are also high in Sirsali village according to Deans classification grading normal (2), questionable (4), very mild (4), mild (3) and moderate (2) village followed by Peelwa, normal (5), questionable (4), very mild (2), mild (3) and moderate (1),
Table 1: Fluoride concentration in drinking water sources of the selected five villages

District: Jaipur 1. Block: Jamwa Ramgarh

\begin{tabular}{lll}
\hline S. No. & Name of village & $\begin{array}{l}\text { Fluoride concentration in drinking } \\
\text { water sources } \\
\text { Range (ppm)* }\end{array}$ \\
\hline 1 & Nayabas & $0.7-2.10$ \\
2 & Heerawala & $0.8-2.70$ \\
3 & Paleda & $1.00-2.80$ \\
4 & Saipur & $2.20-9.50$ \\
5 & Birasana & $2.50-15.00$ \\
\hline *Dinking water sources: Hand pump, Tube well, ppm: Parts per million
\end{tabular}

Table 2: Fluoride concentration in drinking water sources of the selected five villages

District: Jaipur 2. Block: Amber

\begin{tabular}{lll}
\hline S. No. & Name of village & $\begin{array}{l}\text { Fluoride concentration in drinking } \\
\text { water sources } \\
\text { Range (ppm)* }\end{array}$ \\
\hline 1 & Chitanu kalan & $1.40-2.20$ \\
2 & Jugalpura & $0.80-2.50$ \\
3 & Sunder ka bas & $0.90-2.50$ \\
4 & Peelwa & $0.80-3.50$ \\
5 & Sirsali & $2.20-5.10$ \\
\hline
\end{tabular}

Drinking water sources: Hand pump, Tube well, ppm: Parts per million
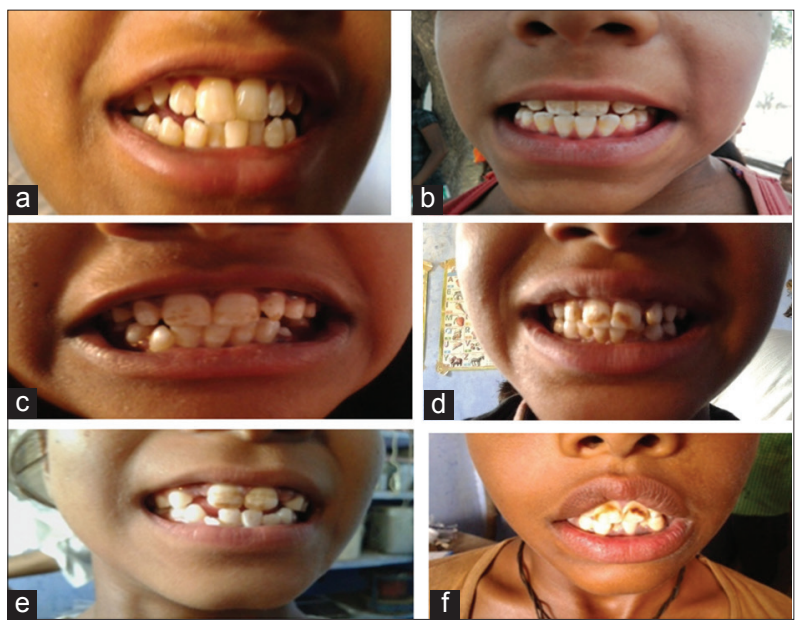

Fig. 1: Dental fluorosis (Dean's grading), (a) normal (Grade 0)

(b) questionable (Grade 1), (c) very mild (Grade 2), (d) mild (Grade 3), (e) moderate (Grade 4) and (f) severe (Grade 5)

Sunder ka bas normal (7), questionable (3), very mild (2) mild (2) and moderate (1), Jugalpura normal (8), questionable (3), very mild (3) and mild (1), and Chitanukalan normal (9), questionable (4), very mild (2) and over all the prevalence of DF 26 (34.66\%) in Amber block out of 75 children were examined in Jaipur district, Rajasthan (Table 4).

The fluoride ( $F$ ) concentration was estimated in source of drinking water which ranges from ( 0.7 to 15 ppm) in Jamwa Ramgarh block and (1.40 to $5.10 \mathrm{ppm}$ ) in Amber block of Jaipur district, Rajasthan has shown in (Tables 1 and 2). The fluoride content in drinking water $1.5 \mathrm{ppm}$ was prescribed by the WHO [26]. This indicates that the occurrence of fluorosis in an area can be affected by so many other factors such as different life styles, nutritional status, climate, altitude, individual susceptibility and biological response, duration of $\mathrm{F}$ exposure and dissolved salts in drinking water [27]. Inorganic pollutants in ground water are hazardous for human health [28]. In Rajasthan, Indigenous rocks are rich source of fluoride contaminated water and ground water around the mica mines, Rajasthan has rich sources of mica. 
Table 3: Dental fluorosis Dean's classification (grading) of children of Jaipur district of Rajasthan 1. Block: Jamwa Ramgarh

\begin{tabular}{|c|c|c|c|c|c|c|c|c|c|}
\hline \multirow[t]{3}{*}{ S. No. } & \multirow{3}{*}{$\begin{array}{l}\text { Name of } \\
\text { village }\end{array}$} & \multirow{3}{*}{$\begin{array}{l}\text { No. of children } \\
\text { examined } \\
\text { age (6-14 years) }\end{array}$} & \multicolumn{6}{|c|}{ Dean's classification (grading) } & \multirow{3}{*}{$\begin{array}{l}\text { Prevalence } \\
\text { of DF in } \\
\text { children (\%) }\end{array}$} \\
\hline & & & \multicolumn{2}{|l|}{ Control } & \multicolumn{4}{|l|}{ Cases } & \\
\hline & & & 0 (Normal) & 1 (Questionable) & 2 (Very mild) & 3 (Mild) & 4 (Moderate) & 5 (Severe) & \\
\hline 1 & Paleda & 15 & 4 & 6 & 2 & 3 & - & - & $5(33.33)$ \\
\hline 2 & Heerawala & 15 & 8 & 4 & 2 & 1 & - & - & $3(20)$ \\
\hline 3 & Nayabas & 15 & 10 & 3 & 2 & - & - & - & $2(13.33)$ \\
\hline 4 & Saipur & 15 & 3 & 5 & 3 & 3 & 1 & - & $7(46.66)$ \\
\hline Total & & 75 & 27 & 21 & 11 & 10 & 4 & 2 & $27(36)$ \\
\hline
\end{tabular}

Table 4: Dental fluorosis Dean's classification (grading) of children of Jaipur district of Rajasthan 2. Block: Amber

\begin{tabular}{|c|c|c|c|c|c|c|c|c|c|}
\hline \multirow[t]{3}{*}{ S. No. } & \multirow{3}{*}{$\begin{array}{l}\text { Name of } \\
\text { village }\end{array}$} & \multirow{3}{*}{$\begin{array}{l}\text { No. of children } \\
\text { examined } \\
\text { age (6-14 years) }\end{array}$} & \multicolumn{6}{|c|}{ Dean's classification (grading) } & \multirow{3}{*}{$\begin{array}{l}\text { Prevalence } \\
\text { of DF in } \\
\text { children } \\
(\%)\end{array}$} \\
\hline & & & \multicolumn{2}{|l|}{ Control } & \multicolumn{4}{|l|}{ Cases } & \\
\hline & & & 0 (Normal) & 1 (Questionable) & 2 (Very mild) & 3 (Mild) & 4 (Moderate) & 5 (Severe) & \\
\hline 1 & Chitanu kalan & 15 & 9 & 4 & 2 & - & - & - & $2(13.33)$ \\
\hline 2 & Jugalpura & 15 & 8 & 3 & 3 & 1 & - & - & $4(26.66)$ \\
\hline 3 & Sunder ka bas & 15 & 7 & 3 & 2 & 2 & 1 & - & $5(33.33)$ \\
\hline 4 & Peelwa & 15 & 5 & 4 & 2 & 3 & 1 & - & $6(40)$ \\
\hline Total & & 75 & 31 & 18 & 13 & 9 & 4 & - & $26(34.66)$ \\
\hline
\end{tabular}

DF: Dental fluorosis

The prevalence of DF 27 (36\%) in Jamwa Ramgarh block and 26 (34.66\%) in Amber block out of 75 children were examined in each block as shown in (Tables 3 and 4). Our study finding data show the DF cases are higher in the Jamwa Ramgarh block as compare to Amber block. Many studies in the past have proved the direct link between the concentration of fluoride in source of drinking water and degree of dental fluorosis in the many communities and countries [29-32].

In India, previous study of DF has been reported in human's intake of fluoride $(\mathrm{F})$ concentration which ranges from ( 0.5 to $1.0 \mathrm{ppm})$ in drinking water $[13,33]$. Hundred percentage of DF has been reported where fluoride concentrations of 3.4-3.8 ppm in drinking water [14,34]. The present study revealed that the drinking water of the investigated region was contaminated with fluoride and the children of the study area were chronically exposed to higher levels of $\mathrm{F}$ from drinking water sources. In the present investigation, in summary, as well as the water $\mathrm{F}$ levels being positively correlated with the severity of DF in the children. However, due to the many limitations in this study, more research with larger sample sizes is needed to arrive at any conclusion.

\section{CONCLUSION}

This study data shows the prevalence of DF 27 (36\%) in Jamwa Ramgar block and 26 (34.66\%) in Amber block of Jaipur district. A higher level of $\mathrm{F}$ in source of drinking water is a major risk factor for DF in the children. Hence, it is important to control the F content in the drinking water by establishing defluoridation unit. This study also provides the baseline data and information to public health authorities and significant use in planning of appropriate preventive strategies to control the DF problem in the children of Jaipur district, Rajasthan, India.

\section{ACKNOWLEDGMENT}

I wish to express my sincere gratitude to my research supervisor Dr. G.S. Toteja, Director, Desert Medicine Research Centre c/o Model Rural Health Research Unit (Department of Health Research) Bhanpur Kalan, Jaipur, Rajasthan for providing necessary support, encouragement and proper guidance during my research work.

\section{REFERENCES}

1. Park K. Park's Text Book of Preventive and Social Medicine. $21^{\text {st }}$ ed., Vol. 1167. Jabalpur: Banarasis das Bhanot; 2011. p. 577.

2. Wedepohl KH. Hand Book of Geochemistry. Vol. 2. Berlin, Heidelberg, New York: Springer-Verlage; 1974. p. 9K-1.

3. Susheela AK, Kharb P. Aortic calcification in chronic fluoride poisoning: Biochemical and electronmicroscopic evidence. Exp Mol Pathol 1990;53(1):72-80

4. Vasant RA, Narasimhacharya AV. Alleviatory effects of (Emblica Officinalis $\mathrm{G})$. As a food supplement in fluoride induced hyperlipemia and oxidative stress. Int J Pharm Pharm Sci 2012;4(1):404-8.

5. Environmental Protection Agency. Public Health Global for Fluoride in Drinking Water, Pesticide and Environmental Toxicology, Section Office of Environmental Health Hazard Assessment. California: Environmental Protection Agency; 1997.

6. Deshpande RR, Kachare P, Sharangpani G, Varghese VK, Bahulkar NS. Comparative evaluation of antimicrobial efficacy of two commercially available dentifrices (fluoridated and herbal) against salivary microflora. Int J Pharm Pharm Sci 2014;6(6):72-4.

7. Bo Z, Mei H, Yongsheng Z, Xueyu L, Xuelin Z, Jun D. Distribution and risk assessment of fluoride in drinking water in the west plain region of Jilin province, China. Environ Geochem Health 2003;25(4):421-31.

8. Susheela AK. Fluorosis: Indian Scenario: A Treatise on Fluorosis. New Delhi, India: Fluorosis Research and Rural Development Foundation; 2001

9. Nand RS. Observation of fluoride intake in Lucknow. J Indian Dent Assoc 1972;44:177-81.

10. Teotia SP, Teotia M. Endemic fluorosis in India: A challenging national health problem. J Assoc Physicians India 1984;32(4):347-52.

11. Dissendorf $M$. Tooth decay not related to fluoride intake from water. Nature 1986;322:125-9.

12. Harikumar R, Khandare AL, Bhramam GN, Venkiah C, Reddy G, Sivakumar B. Assessment of current status of fluorosis in NorthWestern districts of Tamil Nadu, using community index for dental fluorosis. J Hum Ecol 2007;21(1):27-32.

13. Ray SK, Ghosh S, Nagchaudhuri J, Tiwari IC, Kaur P. Prevalence of fluorosis in rural community near Varanasi. Fluoride 1981;14(2):86-90.

14. Choubsia SL, Sompura K, Bhatt SK, Choubisa DK, Pandya H, Joshi SC, et.al. Prevalence of fluorosis in some villages of Dungarpur district of Rajasthan. Indian J Environ Health 1996;38(2):119-26.

15. Choubisa SL. Fluoride distribution and fluorosis in some villages of 
Banswara district of Rajasthan. Indian J Environ Health 1997;39:281-8.

16. Dean HT, Dixon R, Cohen C. Mottled enamel in Texas. Public Health Rep 1935;50:424-42.

17. Dean HT, Elvolve E. Studies on minimal threshold of the dental sign of chronic endemic fluorosis (mottled enamel). Public Health Rep 1935;50:1719-29.

18. Dean HT. Chronic endemic dental fluorosis (mottled enamel). JAMA 1936;107:1269-72.

19. Dean HT, Elvove E. Some epidemiological aspects of chronic endemic dental fluorosis. Am J Public Health Nations Health 1936;26(6):567-75.

20. Dean HT, Elvolve E. Mottled enamel in South Dakota. Public Health Rep 1939;54:212-28.

21. Krishnamachari KA, Krishnaswamy K. Genu valgum and osteoporosis in an area of endemic fluorosis. Lancet 1973;2(7834):877-9.

22. Yadav JP, Lata S, Kataria SK, Kumar S. Fluoride distribution in groundwater and survey of dental fluorosis among school children in the villages of the Jhajjar District of Haryana, India. Environ Geochem Health 2009;31(4):431-8.

23. Suthar S, Garg VK, Jangir S, Kaur S, Goswami N, Singh S. Fluoride contamination in drinking water in rural habitations of Northern Rajasthan, India. Environ Monit Assess 2008;145(1-3):1-6.

24. Dean HT. The Investigation of physiological effects by the epidemiological method. In: Moulton FR, editor. Fluorine and Dental Health. Vol. 19. Washington, DC: American Association for the Advancement of Science; 1942. p. 23-31.
25. Hall LL, Smith FA, De Lopez OH, Gardner DE. Direct potentiometric determination of total ionic fluoride in biological fluids. Clin Chem 1972;18(12):1455-8.

26. WHO. Guideline for Drinking-Water Quality. $3^{\text {rd }}$ ed. Geneva, Switzerland: World Health Organization; 2004. p. 516.

27. Choubisa SL. Endemic fluorosis in Southern Rajasthan, India. Fluoride 2001;34(1):61-70.

28. Shah B, Pandya D, Patel H, Ayalew A, Shah A. Zeolitic composites from agricultural detritus for pollution remedy: A review. J Crit Rev 2016;3(3):41-9.

29. Griffin SO, Beltrán ED, Lockwood SA, Barker LK. Esthetically objectionable fluorosis attributable to water fluoridation. Community Dent Oral Epidemiol 2002;30(3):199-209.

30. Al-Shammery AR, Guile EE, Backly ME. The prevalence of dental fluorosis in Saudi Arabia. Saudi Dent J 1997;9(2):58-61.

31. Ishii T, Suckling G. The severity of dental fluorosis in children exposed to water with a high fluoride content for various periods of time. J Dent Res 1991;70(6):952-6.

32. Warren JJ, Levy SM, Kanellis MJ. Prevalence of dental fluorosis in the primary dentition. J Public Health Dent 2001;61(2):87-91.

33. Venkaleswarla P, Rao DN, Rao KR. Studies in endemic fluorosis in Vishakhapatanam and suburban areas. Indian J Med Res 1952;40(4):353-62.

34. Subbareddy VV, Tewari A. Enamel mottling at different levels of fluoride in drinking water: In an endemic area. J Indian Dent Assoc 1985;57(6):205-12. 